\title{
Parental Education and Genetics of BMI from Infancy to Old Age: A Pooled Analysis of 29 Twin Cohorts
}

\author{
Karri Silventoinen (DD 1,2, Aline Jelenkovic ${ }^{1,3}$, Antti Latvala ${ }^{4,5}$, Yoshie Yokoyama ${ }^{6}$, Reijo Sund $^{1,7}$, Masumi Sugawara $^{8}$, \\ Mami Tanaka ${ }^{9}$, Satoko Matsumoto ${ }^{10}$, Sari Aaltonen ${ }^{1,5}$, Maarit Piirtola ${ }^{1,5}$, Duarte L. Freitas ${ }^{11}$, José A. Maia ${ }^{12}$, \\ Sevgi Y. Öncel ${ }^{13}$, Fazil Aliev ${ }^{14}$, Fuling Ji (D) ${ }^{15}$, Feng Ning ${ }^{15}$, Zengchang Pang ${ }^{15}$, Esther Rebato ${ }^{3}$, Kimberly J. Saudino ${ }^{16}$, \\ Tessa L. Cutler ${ }^{17}$, John L. Hopper ${ }^{17,18}$, Vilhelmina Ullemar ${ }^{19}$, Catarina Almqvist ${ }^{19,20}$, Patrik K. E. Magnusson ${ }^{19}$, \\ Wendy Cozen ${ }^{21,22}$, Amie E. Hwang ${ }^{21}$, Thomas M. Mack ${ }^{21,22}$, Gonneke Willemsen ${ }^{23}$, Meike Bartels ${ }^{23}$, \\ Catharina E. M. van Beijsterveldt ${ }^{23}$, Tracy L. Nelson ${ }^{24}$, Keith E. Whitfield ${ }^{25}$, Joohon Sung ${ }^{18,26}$, Jina Kim ${ }^{18}$, \\ Jooyeon Lee ${ }^{18}$, Sooji Lee ${ }^{18}$, Clare H. Llewellyn ${ }^{27}$, Abigail Fisher ${ }^{27}$, Emanuela Medda ${ }^{28}$, Lorenza Nisticò ${ }^{28}$, \\ Virgilia Toccaceli ${ }^{28}$, Laura A. Baker ${ }^{29}$, Catherine Tuvblad ${ }^{29,30}$, Robin P. Corley ${ }^{31}$, Brooke M. Huibregtse (D) ${ }^{32}$, \\ Catherine A. Derom ${ }^{33,34}$, Robert F. Vlietinck ${ }^{33}$, Ruth J. F. Loos ${ }^{35}$, Ariel Knafo-Noam ${ }^{36}$, David Mankuta ${ }^{37}$, \\ Lior Abramson ${ }^{36}$, S. Alexandra Burt ${ }^{38}$, Kelly L. Klump ${ }^{38}$, Judy L. Silberg ${ }^{39}$, Hermine H. Maes ${ }^{39,40,41}$, \\ Robert F. Krueger ${ }^{42}$, Matt McGue ${ }^{42}$, Shandell Pahlen ${ }^{42}$, Margaret Gatz ${ }^{19,43}$, David A. Butler ${ }^{44}$, Jennifer R. Harris ${ }^{45}$, \\ Thomas S. Nilsen ${ }^{45}$, K. Paige Harden ${ }^{46}$, Elliot M. Tucker-Drob ${ }^{46}$, Carol E. Franz ${ }^{47}$, William S. Kremen ${ }^{47,48}$, \\ Michael J. Lyons ${ }^{49}$, Paul Lichtenstein ${ }^{19}$, Hoe-Uk Jeong ${ }^{50}$, Yoon-Mi Hur ${ }^{50}$, Dorret I. Boomsma ${ }^{23}$, \\ Thorkild I. A. Sørensen ${ }^{51,52}$, and Jaakko Kaprio ${ }^{4,5}$
}

\begin{abstract}
${ }^{1}$ Department of Social Research, University of Helsinki, Helsinki, Finland. Correspondence: Karri Silventoinen (karri.silventoinen@helsinki.fi) ${ }^{2}$ Graduate School of Medicine, Osaka University, Osaka, Japan ${ }^{3}$ Department of Genetics, Physical Anthropology and Animal Physiology, University of the Basque Country, Leioa, Spain ${ }^{4}$ Department of Public Health, University of Helsinki, Helsinki, Finland ${ }^{5}$ Institute for Molecular Medicine Finland, Helsinki, Finland ${ }^{6}$ Department of Public Health Nursing, Osaka City University, Osaka, Japan ${ }^{7}$ Institute of Clinical Medicine, University of Eastern Finland, Kuopio, Finland ${ }^{8}$ Department of Psychology, Ochanomizu University, Tokyo, Japan ${ }^{9}$ Center for Forensic Mental Health, Chiba University, Chiba, Japan ${ }^{10}$ Institute for Education and Human Development, Ochanomizu University, Tokyo ${ }^{11}$ Department of Physical Education and Sport, University of Madeira, Funchal, Portugal ${ }^{12}$ Faculty of Sport, University of Porto, Porto, Portugal ${ }^{13}$ Department of Statistics, Faculty of Arts and Sciences, Kirıkkale University, Kırıkkale, Turkey ${ }^{14}$ Departments of Psychology and African American Studies, Virginia Commonwealth University, Richmond, Virginia, USA ${ }^{15}$ Department of Noncommunicable Diseases Prevention, Qingdao Centers for Disease Control and Prevention, Qingdao, China ${ }^{16}$ Department of Psychological and Brain Sciences, Boston University, Boston, Massachusetts, USA ${ }^{17}$ The Australian Twin Registry, Centre for Epidemiology and Biostatistics, University of Melbourne, Melbourne, Victoria, Australia ${ }^{18}$ Department of Epidemiology, School of Public Health, Seoul National University, Seoul, South Korea ${ }^{19}$ Department of Medical Epidemiology and Biostatistics, Karolinska Institutet, Stockholm, Sweden ${ }^{20}$ Pediatric Allergy and Pulmonology Unit, Astrid Lindgren Children's Hospital, Karolinska University Hospital, Stockholm, Sweden ${ }^{21}$ Department of Preventive Medicine, Keck School of Medicine, University of Southern California, Los Angeles, California, USA ${ }^{22}$ USC Norris Comprehensive Cancer Center, University of Southern California, Los Angeles, California, USA ${ }^{23}$ Netherlands Twin Register, Department of Biological Psychology, Vrije Universiteit Amsterdam, Amsterdam, Netherlands ${ }^{24}$ Department of Health and Exercise Sciences, Colorado School of Public Health, Colorado State University, Fort Collins, Colorado, USA ${ }^{25}$ Department of Psychology and Neuroscience, Duke University, Durham, North Carolina, USA ${ }^{26}$ Institute of Health and Environment, Seoul National University, Seoul, South Korea ${ }^{27}$ Health Behaviour Research Centre, Department of Epidemiology and Public Health, Institute of Epidemiology and Health Care, University College London, London, UK ${ }^{28}$ Center for Behavioral Sciences and Mental Health, Higher Institute of Health, Rome, Italy ${ }^{29}$ Department of Psychology, University of Southern California, Los Angeles, California, USA ${ }^{30}$ School of Law, Psychology and Social Work, Örebro University, Örebro, Sweden ${ }^{31}$ Institute for Behavioral Genetics, University of Colorado, Boulder, Colorado, USA ${ }^{32}$ Institute of Behavioral Science, University of Colorado, Boulder, Colorado, USA ${ }^{33}$ Center of Human Genetics, University Hospitals Leuven, Leuven, Belgium ${ }^{34}$ Department of Obstetrics and Gynecology, Ghent University Hospitals, Ghent, Belgium ${ }^{35}$ The Charles Bronfman Institute for Personalized Medicine, The Mindich Child Health and Development Institute, Icahn School of Medicine at Mount Sinai, New York, New York, USA ${ }^{36}$ Psychology Department, The Hebrew University of Jerusalem, Jerusalem, Israel ${ }^{37}$ Obstetrics and Gynecology Department, Hadassah Hospital, Hebrew University Medical School, Jerusalem, Israel ${ }^{38}$ Department of Psychology, Michigan State University, East Lansing, Michigan, USA ${ }^{39}$ Department of Human and Molecular Genetics, Virginia Institute for Psychiatric and Behavioral Genetics, Virginia Commonwealth University, Richmond, Virginia, USA ${ }^{40}$ Department of Psychiatry, Virginia Institute for Psychiatric and Behavioral Genetics, Virginia Commonwealth University, Richmond, Virginia, USA ${ }^{41}$ Massey Cancer Center, Virginia Commonwealth University, Richmond, Virginia, USA ${ }^{42}$ Department of Psychology, University of Minnesota, Minneapolis, Minnesota, USA ${ }^{43}$ Center for Economic and Social Research, University of Southern California, Los Angeles, California, USA ${ }^{44}$ Health and Medicine Division, The National Academies of Sciences, Engineering, and Medicine, Washington, DC, USA ${ }^{45}$ Norwegian Institute of Public Health, Oslo, Norway ${ }^{46}$ Department of Psychology, University of Texas at Austin, Austin, Texas, USA ${ }^{47}$ Department of Psychiatry, University of California, San Diego, San Diego, California, USA ${ }^{48}$ VA San Diego Center of Excellence for Stress and Mental Health, La Jolla, California, USA ${ }^{49}$ Department of Psychology, Boston University, Boston, Massachusetts, USA ${ }^{50}$ Department of Education, Mokpo National University, Jeonnam, South Korea ${ }^{51}$ Section of Metabolic Genetics, Novo Nordisk Foundation Center for Basic Metabolic Research, Faculty of Health and Medical Sciences, University of Copenhagen, Copenhagen, Denmark ${ }^{52}$ Section of Epidemiology, Department of Public Health, Faculty of Health and Medical Sciences, University of Copenhagen, Copenhagen, Denmark.
\end{abstract}


Objective: The objective of this study was to analyze how parental education modifies the genetic and environmental variances of BMI from infancy to old age in three geographic-cultural regions.

Methods: A pooled sample of 29 cohorts including 143,499 twin individuals with information on parental education and BMl from age 1 to 79 years $(299,201$ BMl measures) was analyzed by genetic twin modeling.

Results: Until 4 years of age, parental education was not consistently associated with BMI. Thereafter, higher parental education level was associated with lower BMI in males and females. Total and additive genetic variances of BMI were smaller in the offspring of highly educated parents than in those whose parents had low education levels. Especially in North American and Australian children, environmental factors shared by co-twins also contributed to the higher BMI variation in the low education level category. In Europe and East Asia, the associations of parental education with mean BMI and BMI variance were weaker than in North America and Australia.

Conclusions: Lower parental education level is associated with higher mean BMl and larger genetic variance of BMI after early childhood, especially in the obesogenic macro-environment. The interplay among genetic predisposition, childhood social environment, and macro-social context is important for socioeconomic differences in BMI.

Obesity (2019) 27, 856-865. doi:10.1002/oby.22451

\section{Introduction}

Mean body mass index (BMI; in kilograms per meter squared) has increased all over the industrialized world during the past four decades and currently shows clear geographic differences, with the highest BMIs in North America and the lowest BMIs in East Asia (1). Twin studies have shown that genetic factors explain a substantial proportion of BMI variation over the life course (2,3), and genome-wide association (GWA) studies have identified the role of genetic variants behind BMI variation $(4,5)$. There is also strong evidence for higher BMI in lower socioeconomic classes in Western industrialized societies (6). The roots of socioeconomic obesity differences may already emerge in childhood because many socioeconomic characteristics of the childhood family, such as parental education and income, are associated

Funding agencies: This study was conducted within the Collaborative Project of Development of Anthropometrical Measures in Twins (Academy of Finland Grant 266592). Funding for individual collaborators is as follows. The Child and Adolescent Twin Study in Sweden is supported by the Swedish Research Council through the Swedish Initiative for Research on Microdata in the Social and Medical Sciences Framework Grant 340-2013-5867, grants provided by the Stockholm County Council (ALF projects), the Swedish Heart-Lung Foundation, and the Swedish Asthma and Allergy Association's Research Foundation. The Netherlands Twin Register acknowledges support from the Netherlands Organization for Scientific Research and MagW/ZonMW Grants 904-61-090, 985-10-002, 912-10-020, 904-61-193,480-04-004, 463-06-001, 451-04-034, 400-05-717, Addiction-31160008, Middelgroot-911-09-032, and Spinozapremie-56-464-14192; Vrije University's Institute for Health and Care Research; the European Research Council (ERC; grant 230374); and the Avera Institute, Sioux Falls, South Dakota. Data collection and analyses in Finnish twin cohorts have been supported by the European Network for Genetic and Genomic Epidemiology (ENGAGE; FP7-HEALTH-F4-2007, grant agreement 201413), the National Institute of Alcohol Abuse and Alcoholism (grants AA-12502, AA-00145, and AA-09203 to R. J. Rose), the Academy of Finland Center of Excellence in Complex Disease Genetics (grants 213506 and 129680), and the Academy of Finland (grants 100499, 205585, 118555, 141054, 265240, 264146, and 312073 to J. Kaprio). Since its origin, the East Flanders Prospective Survey has been partly supported by grants from the Fund of Scientific Research, Flanders and Twins, a nonprofit Association for Scientific Research in Multiple Births (Belgium). Gemini was supported by a grant from Cancer Research UK (C1418/A7974). Data collection and research stemming from the Norwegian Twin Registry are supported, in part, by the European Union's Seventh Framework Programmes ENGAGE Consortium (grant agreement HEALTH-F4-2007-201413) and Biobank Standardization and Harmonization for Research Excellence in the European Union (grant agreement HEALTH-F4-2010-261433). Madeira data come from Genetic and Environmental Influences on Physical Activity, Fitness and Health: the Madeira Family Study (project reference: POCI/DES/56834/2004, founded by the Portuguese agency for research [the Foundation for Science and Technology]). S. Y. Öncel and F. Aliev are supported by a Kirıkkale University research grant (2009/43) and a Scientific and Technological Research Council of Turkey grant (114C117). K. Silventoinen is supported by Osaka University's International Joint Research Promotion Program. The Boston University Twin Project is funded by grants (R01HD068435 and R01MH062375) from the National Institutes of Health (NIH) to K. J. Saudino. The California Twin Program was supported by the California Tobacco-Related Disease Research Program (7RT-0134H, 8RT-0107H, and 6RT-0354H) and NIH (1R01ESO15150-01). The Carolina African American Twin Study of Aging was funded by a grant from the National Institute on Aging (NIA; 1R01AG13662-01A2) to K. E. Whitfield. The Colorado Twin Registry is funded by National Institute on Drug Abuse grant DA011015 and Longitudinal Twin Study grant HD10333; B. M. Huibregtse is supported by 5T32DA017637 and 5T32AG052371. The Michigan State University (MSU) Twin Registry has been supported by MSU, as well as by grants R01MH081813, R01MH0820-54, R01MH092377-02, R21MH070542-01, and R03MH63851-01 from the National Institute of Mental Health (NIMH), grant R01HD066040 from the Eunice Kennedy Shriver National Institute of Child Health and Human Development (NICHD), and grant 11-SPG-2518 from the MSU Foundation. The content of this manuscript is solely the responsibility of the authors and does not necessarily represent the official views of $\mathrm{NIMH}, \mathrm{NICHD}$, or NIH. The University of Southern California Twin Study is funded by a grant from NIMH (R01MH58354). The Texas Twin Project is currently funded by grants AA023322 and HD081437 from NIH. The Vietnam Era Twin Study of Aging was supported by NIH/NIA grants R01AG018384, R01AG018386, R01AG022381, and R01AG022982 and, in part, with resources of the VA San Diego Center of Excellence for Stress and Mental Health. The Cooperative Studies Program of the Office of Research \& Development of the US Department of Veterans Affairs (VA) has provided financial support for the development and maintenance of the Vietnam Era Twin Registry. The content of this manuscript is solely the responsibility of the authors and does not necessarily represent the official views of NIA/NIH or VA. The National Academy of Sciences-National Research Council Twin Registry acknowledges financial support from NIH grant R21AG039572. The Korean TwinFamily Register was supported by the Global Research Network Program of the National Research Foundation (NRF; 2011-220-E00006). The South Korea Twin Registry is supported by the NRF of Korea (NRF-371-2011-1 B00047). The West Japan Twins and Higher Order Multiple Births Registry was supported by a Grantin-Aid for Scientific Research (B) (15H05105) from the Japan Society for the Promotion of Science. This research was facilitated through access to Twins Research Australia, a national resource supported by a Centre of Research Excellence Grant (1079102) from the National Health and Medical Research Council. The Longitudinal Israeli Study of Twins was funded by Starting Grant 240994 from the ERC to A. Knafo-Noam.

Disclosure: The authors declared no conflict of interest. 
with the BMI of offspring (7). Adoption studies have supported these findings by showing that lower socioeconomic status of biologically unrelated adoptive families is associated with higher BMI of adopted children as adults (8).

The association of genes and environmental factors with BMI may be modified by sociodemographic characteristics. In our previous study based on the same database as this present study, we found that the genetic variation of adult BMI increased from the 1940s to the 2010s at the same time that mean BMI dramatically increased (3), confirming the earlier findings based on Danish (9) and Swedish data (10). A Dutch twin study of parental education in children and adolescents (11), as well as studies on education of Danish (12) and US adults (13), suggested increased genetic BMI variation associated with less education. However, a Finnish twin study reported that in adolescence, the increased BMI variation in the offspring of parents with less education was attributable to environmental factors shared by co-twins (14).

Addressing the question of how modification of genetic and environmental influences on BMI develops over the human life-span requires considerable statistical power. Thus, we analyzed whether and how parental education modifies the genetic and environmental variation of BMI from infancy to old age in a very large international database of twins. Further, we analyzed whether the interaction between parental education and BMI varies among three geographic-cultural regions that are characterized by different levels of mean BMI in the population, indicating different obesogenic environments.

\section{Methods}

The data were derived from the Collaborative Project of Development of Anthropometrical Measures in Twins (CODATwins) targeted to collect all available twin data on height and weight in the world (15). We included 29 twin cohorts with additional information on maternal and paternal education. Eleven cohorts came from European countries, five cohorts came from East Asian countries, eleven cohorts came from the United States, and single cohorts came from Australia and Israel. The names of participating cohorts are given in Table 1 (legend). Age was classified into 1-year age categories from 1 to 19 years of age, and after that, 10-year categories were defined. Participants who were 80 years of age or older were excluded (319 measures) because of decreasing muscle mass at old age (16). Together, there were 324,329 BMI measurements. In children and adolescents, we checked the BMI distribution in each age and sex group and removed the extreme, likely erroneous values (658 measures representing $0.3 \%$ of the measurements at 19 years of age or younger corresponding to values approximately 3 SDs less than or greater than the mean). In adults, we removed the measurements consistent with anorexia nervosa (BMI $<15 \mathrm{~kg} / \mathrm{m}^{2}$, 96 measures representing $0.1 \%$ of adult measures) and morbid obesity $\left(\mathrm{BMI}>45 \mathrm{~kg} / \mathrm{m}^{2}, 246\right.$ measures representing $0.3 \%$ of adult measures). Thus, our results represent the range of normal BMI variation and do not represent extremely low and very high BMI values, which may be affected by specific factors such as anorexia nervosa or rare monogenic traits. To confirm that all parameter estimates were based on independent observations, we selected one measurement in each age group from cohorts with repeated measures and conducted independent models in each age group. In the present analyses, 299,201 BMI measures from 143,499 twin individuals (52\% females) including 66,165 complete twin pairs (39\% monozygotic [MZ], 34\% samesex dizygotic [DZ], and $27 \%$ opposite-sex DZ) with information on maternal and paternal education were used. All participants were volunteers who gave informed consent when participating in their original studies. The pooled analysis was approved by the ethical committee of the Department of Public Health, University of Helsinki.

The different educational classifications used in the surveys were transformed as educational years, as described elsewhere (17). We first calculated regression residuals of maternal and paternal education separately by fitting a regression model with maternal or paternal education as the dependent variable and twin cohort and the birth year of their twin children, used as a proxy indicator for the birth years of parents, as independent variables. Twin cohort was treated as a nominal-level variable with a dummy variable for each individual cohort and birth year as a continuous variable. These residuals were then summed up to get combined parental education and divided into three categories (less than $-0.5 \mathrm{SDs}$ from the mean, from -0.5 to $0.5 \mathrm{SDs}$ from the mean, and more than $0.5 \mathrm{SDs}$ from the mean) to indicate low (31\% of participants), average (40\% of participants), and high parental education levels (29\% of participants). The SD of parental education was slightly higher in North America and Australia $(\mathrm{SD}=5.33)$ than in Europe $(\mathrm{SD}=4.50)$ and East Asia (SD = 4.10). However, we calculated the residuals in the full cohort and used the same categorization of parental education to avoid changing the educational distribution and to confirm the same extent of education in all geographic-cultural regions. Thus, the residuals indicate how much shorter or longer the parental education duration is as compared with that of the average person having a certain birth year in each twin cohort. Correspondingly, BMI was adjusted for the effects of exact age and twin cohort in each age and sex category by regression models.

In the aggregation of twin cohorts by the geographic-cultural regions, we removed Turkey from all region-specific analyses because the Turkish population is genetically distinct from other European populations (18). We also combined the cohort from Australia with North American cohorts because the mean BMI in Australia is closer to that in North American than European countries (1). Thus, we had three geographic-cultural regions (North America and Australia, Europe, and East Asia) representing the high, intermediate, and low levels of obesogenic factors in the environment, respectively, based on the mean BMI of population (1). The same classification was also used in our previous studies on the genetics of BMI in childhood (2) and adulthood (3), which were based on the CODATwins database. The number of BMI measurements was highest in Europe (196,990 measures), followed by North America and Australia (82,098 measures) and East Asia (18,670 measures). Because there was more ethnic diversity in North America and Australia than in the other cultural-geographic regions, we repeated the main analyses in North Americans and Australians of Caucasian ethnicity based on self-reports (75,973 measures).

We used structural equation modeling to estimate genetic and environmental variance components (19). Genetic twin modeling is based on the different genetic relatedness of MZ and DZ twins: DZ twins share, on average, $50 \%$ of their genes (identical by descent); MZ twins are virtually identical at the DNA-sequence level. Based on this principle, the BMI variation can be decomposed into additive genetic variation (additive effects of all loci affecting BMI), dominance genetic variation (nonadditive genetic effects), shared environmental variation (all environmental effects making co-twins similar), and unique environmental variation (all environmental effects making co-twins different and measurement error). Models were fitted separately for each parental education category by age groups. 


\begin{tabular}{|c|c|c|c|c|c|c|c|c|c|c|c|c|c|c|}
\hline \multirow[b]{3}{*}{ Age } & \multicolumn{7}{|c|}{ Males } & \multicolumn{7}{|c|}{ Females } \\
\hline & \multirow[b]{2}{*}{$N$} & \multicolumn{2}{|c|}{$\mathrm{BMI}\left(\mathrm{kg} / \mathrm{m}^{2}\right)$} & \multicolumn{2}{|c|}{$\begin{array}{c}\text { Maternal } \\
\text { education (y) }\end{array}$} & \multicolumn{2}{|c|}{$\begin{array}{c}\text { Paternal } \\
\text { education }(y)\end{array}$} & \multirow[b]{2}{*}{$N$} & \multicolumn{2}{|c|}{ BMI $\left(\mathrm{kg} / \mathrm{m}^{2}\right)$} & \multicolumn{2}{|c|}{$\begin{array}{c}\text { Maternal } \\
\text { education (y) }\end{array}$} & \multicolumn{2}{|c|}{$\begin{array}{c}\text { Paternal } \\
\text { education (y) }\end{array}$} \\
\hline & & Mean & SD & Mean & SD & Mean & SD & & Mean & SD & Mean & SD & Mean & SD \\
\hline 1 & 13,548 & 17.1 & 1.36 & 13.8 & 2.31 & 13.9 & 2.6 & 14,023 & 16.7 & 1.37 & 13.8 & 2.33 & 13.9 & 2.63 \\
\hline 2 & 11,273 & 16.5 & 1.37 & 14.0 & 2.42 & 14.0 & 2.70 & 11,324 & 16.2 & 1.37 & 14.0 & 2.44 & 13.9 & 2.76 \\
\hline 3 & 10,907 & 15.9 & 1.32 & 14.2 & 2.49 & 14.2 & 2.73 & 11,460 & 15.6 & 1.37 & 14.2 & 2.51 & 14.1 & 2.76 \\
\hline 4 & 3,533 & 15.9 & 1.68 & 15.3 & 3.39 & 14.7 & 3.61 & 3,579 & 15.7 & 1.68 & 15.4 & 3.38 & 14.7 & 3.68 \\
\hline 5 & 6,533 & 15.3 & 1.58 & 14.4 & 2.61 & 14.3 & 2.82 & 6,577 & 15.1 & 1.66 & 14.3 & 2.53 & 14.3 & 2.84 \\
\hline 6 & 1,898 & 15.7 & 1.95 & 15.1 & 3.07 & 14.9 & 3.23 & 1,998 & 15.5 & 1.98 & 15.2 & 3.11 & 14.9 & 3.32 \\
\hline 7 & 7,084 & 15.4 & 1.78 & 14.3 & 2.44 & 14.3 & 2.64 & 7,499 & 15.4 & 1.94 & 14.2 & 2.48 & 14.3 & 2.71 \\
\hline 8 & 4,388 & 15.8 & 2.06 & 14.4 & 2.80 & 14.3 & 2.89 & 4,503 & 15.8 & 2.22 & 14.4 & 2.79 & 14.3 & 2.95 \\
\hline 9 & 3,497 & 16.7 & 2.60 & 14.7 & 3.14 & 14.4 & 3.23 & 3,471 & 16.7 & 2.76 & 14.8 & 3.12 & 14.5 & 3.28 \\
\hline 10 & 7,017 & 16.6 & 2.39 & 14.1 & 2.57 & 14.2 & 2.71 & 7,417 & 16.7 & 2.50 & 14.0 & 2.46 & 14.2 & 2.65 \\
\hline 11 & 3,987 & 17.5 & 2.69 & 13.4 & 3.67 & 12.9 & 4.00 & 4,078 & 17.5 & 2.92 & 13.4 & 3.67 & 12.9 & 4.04 \\
\hline 12 & 6,760 & 17.6 & 2.69 & 13.8 & 2.78 & 13.8 & 3.13 & 7,023 & 17.7 & 2.73 & 13.7 & 2.79 & 13.8 & 3.18 \\
\hline 13 & 3,111 & 18.6 & 3.04 & 14.3 & 2.87 & 14.2 & 3.07 & 3,436 & 18.7 & 3.03 & 14.2 & 2.81 & 14.2 & 3.00 \\
\hline 14 & 5,447 & 19.3 & 2.94 & 13.3 & 3.59 & 12.9 & 3.95 & 6,121 & 19.5 & 3.02 & 13.3 & 3.48 & 12.9 & 3.90 \\
\hline 15 & 3,278 & 20.0 & 3.28 & 14.3 & 2.85 & 14.3 & 3.02 & 3,603 & 20.1 & 3.16 & 14.2 & 2.68 & 14.2 & 2.93 \\
\hline 16 & 3,948 & 20.8 & 3.08 & 13.2 & 3.19 & 13.3 & 3.32 & 4,616 & 20.6 & 2.96 & 13.2 & 3.07 & 13.2 & 3.24 \\
\hline 17 & 5,468 & 21.3 & 2.91 & 13.0 & 3.36 & 12.8 & 3.59 & 6,140 & 20.9 & 2.95 & 13.2 & 3.14 & 13.0 & 3.44 \\
\hline 18 & 4,224 & 21.8 & 2.98 & 12.0 & 3.60 & 11.7 & 4.10 & 3,775 & 21.2 & 3.12 & 12.7 & 3.35 & 12.5 & 3.74 \\
\hline 19 & 2,664 & 22.0 & 2.88 & 12.3 & 3.04 & 12.4 & 3.46 & 3,198 & 21.5 & 3.28 & 13.0 & 2.78 & 13.3 & 3.03 \\
\hline $20-29$ & 10,005 & 23.3 & 3.26 & 12.0 & 3.53 & 11.9 & 3.91 & 12,096 & 22.2 & 3.77 & 12.5 & 3.30 & 12.6 & 3.62 \\
\hline $30-39$ & 7,952 & 25.0 & 3.45 & 11.8 & 2.93 & 12.0 & 3.37 & 11,204 & 23.1 & 4.18 & 11.9 & 2.99 & 12.2 & 3.35 \\
\hline $40-49$ & 9,440 & 25.7 & 3.40 & 11.2 & 3.22 & 11.0 & 3.71 & 8,399 & 24.3 & 4.48 & 11.7 & 3.00 & 11.7 & 3.38 \\
\hline $50-59$ & 4,720 & 26.7 & 3.91 & 11.0 & 3.11 & 10.6 & 3.54 & 3,274 & 24.8 & 4.40 & 10.8 & 3.30 & 10.8 & 3.41 \\
\hline $60-69$ & 4,397 & 26.2 & 3.54 & 10.4 & 3.24 & 10.0 & 3.63 & 2,315 & 24.5 & 3.90 & 10.3 & 3.17 & 10.3 & 3.57 \\
\hline $70-79$ & 2,187 & 25.6 & 3.17 & 10.4 & 3.40 & 9.8 & 3.88 & 806 & 24.2 & 3.93 & 10.0 & 3.26 & 10.4 & 3.79 \\
\hline
\end{tabular}

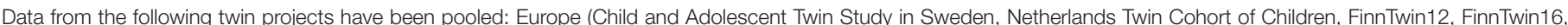

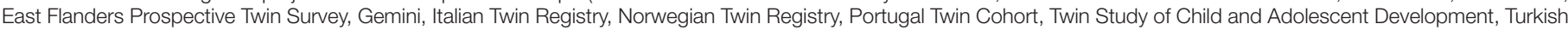

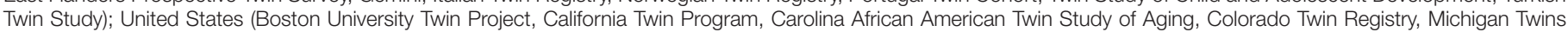

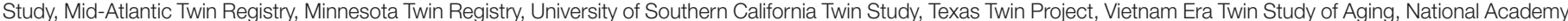

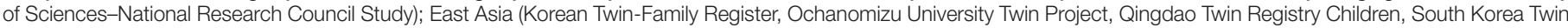
Registry, West Japan Twins and Higher Order Multiple Births Registry); and others (Australian Twin Registry, Longitudinal Israeli Study of Twins).

As we reported previously, slightly higher variances of BMI were found from 6 to 12 years of age in DZ twins compared with MZ twins (20). However, these differences were minor (i.e., 15\% or less) and became statistically significant only because of our very large sample size.

As we have previously reported for children (2) and adults (3), there was little evidence for the presence of dominance genetic variation in BMI. Thus, we used the additive genetic/shared environment/unique environment (ACE) model, which was also supported by the within-pair correlations in all parental education categories in our study cohort (Supporting Information Table S1), in the analyses. We fitted the full model in each age group to get the estimation of the role of shared environmental factors, even when it was not statistically significant in most of the age categories. A clear sex-specific genetic effect for BMI was found in childhood (2) and adulthood (3), and thus all models were fitted to allow the opposite-sex DZ genetic correlation to be lower than the 0.5 expected for same-sex DZ twins.
Especially in early childhood, DZ twins were slightly heavier than MZ twins (20), and thus a different mean BMI was used for MZ and DZ twins.

Next, we fitted gene-environment interaction models to test the significance of the moderator effect of parental education (21). In these models, parental education, used as a continuous variable, was allowed to modify the genetic and environmental variation of BMI. Because weak but systematic shared environmental effects were found for BMI in this database, especially in childhood (2), we fitted both a more parsimonious additive genetic/unique environment model and an ACE model, which needs more statistical power. The genetic models were fitted to the data by the OpenMx package (version 2.0.1) of R statistical software (R Foundation, Vienna, Austria) (22). The effects of parental education on mean BMI were estimated by Stata/SE version 13.1 for Windows statistical software (StataCorp LLC, College Station, Texas). The effect of intrapair correlations on $95 \%$ confidence intervals (CIs) was taken into account by the cluster 
option of Stata. Further, we adjusted these mean modification effects for zygosity because of slight differences in BMI (20) and parental education between MZ and DZ twins (17).

\section{Results}

Table 1 presents the descriptive statistics by age and sex. Mean BMI shows the nadir at 5 years of age and the steady increase until 50 to 59 years of age with modest sex differences. Mean BMI was highest in North America and Australia and lowest in East Asia (Supporting Information Table S2). Maternal and paternal education decreased from the younger to the older age groups, reflecting the increasing levels of education over the birth cohorts. As expected, parental education was virtually identical for males and females.

Figure 1 presents the associations between parental education and BMI. No inverse educational association was seen from 1 to 3 years of age, and the sons of better-educated parents had even a slightly higher BMI. An inverse educational association emerged at 5 years of age in boys and 4 years of age in girls and became stronger until adolescence. In adulthood, the inverse association between parental education and BMI was statistically significant in most of the age groups and stronger in women than in men. In men, this association was somewhat weaker in late adulthood as compared with middle age, but otherwise no systematic differences between the age groups in adulthood were seen.

Figure 2 presents the associations between parental education and BMI in the three cultural-geographic regions. Because most of the BMI measures came from European cohorts, the pattern in Europe followed closely the estimates in the pooled cohort. In North America and Australia, parental education showed stronger associations with mean BMI than in Europe in most of age groups. These differences were more pronounced in females than in males. In East Asia, similar associations were found in females, but because of wider $95 \%$ CIs, they were not statistically significant. However, East Asian males showed no evidence for the association between parental education and BMI.
The total variation of BMI in the three categories of parental education, decomposed to additive genetic, shared environmental, and unique environmental variances, is shown in Figure 3 (the exact estimates with 95\% CIs are provided in Supporting Information Table S3). The total BMI variation was greatest in the low parental education level category and smallest in the high parental education level category in all age groups. With a few exceptions, the BMI variation in the intermediate parental education level category was between the high and low education level categories. In nearly all age groups, the difference in BMI variation between the low and high parental education level categories was statistically significant, as seen by nonoverlapping 95\% CIs (Supporting Information Table S3). When we studied the components of variation, a similar pattern was observed with a few exceptions for additive genetic and unique environmental variances. Except in two age groups, the difference was statistically significant for additive genetic variation, but for unique environmental variation, in nearly half of the age groups, the $95 \%$ CIs overlapped. Shared environmental variance components explained part of the variance, especially in boys and girls of 14 years of age or younger. However, in most of the age groups, they were not statistically significant, and the $95 \%$ CIs also overlapped between the educational categories (Supporting Information Table S3).

The gene-environment interaction models confirmed the results of the stratified analyses (Supporting Information Table S4). When we fitted the additive genetic/unique environment model, in all age groups except for 70- to 79-year-old men, additive genetic modification effects were negative (i.e., higher parental education level was associated with less genetic variation). However, in men 17 years of age or older, girls 3 years of age or younger, and women 50 to 59 years of age or older, the modification effects were weaker than in the other age groups and not significant. Most of the unique environmental modification effects were also negative but were weaker than additive genetic modification effects, and around half of them were not statistically significant. In the ACE model, most of the additive genetic and shared environmental modification effects were negative, but there was more fluctuation in the estimates because of lesser statistical power, and only some of them were statistically significant.
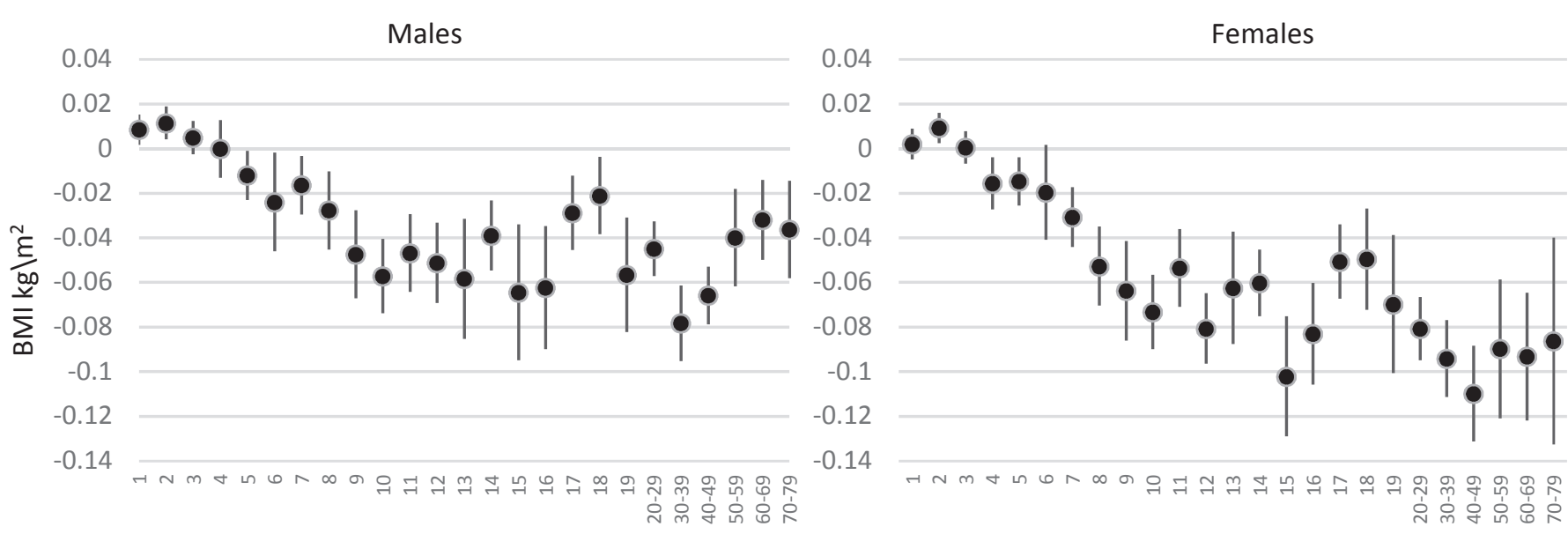

Figure 1 Mean BMI modification effects of parental education with 95\% confidence intervals from 1 until 70 to 79 years of age by sex. 


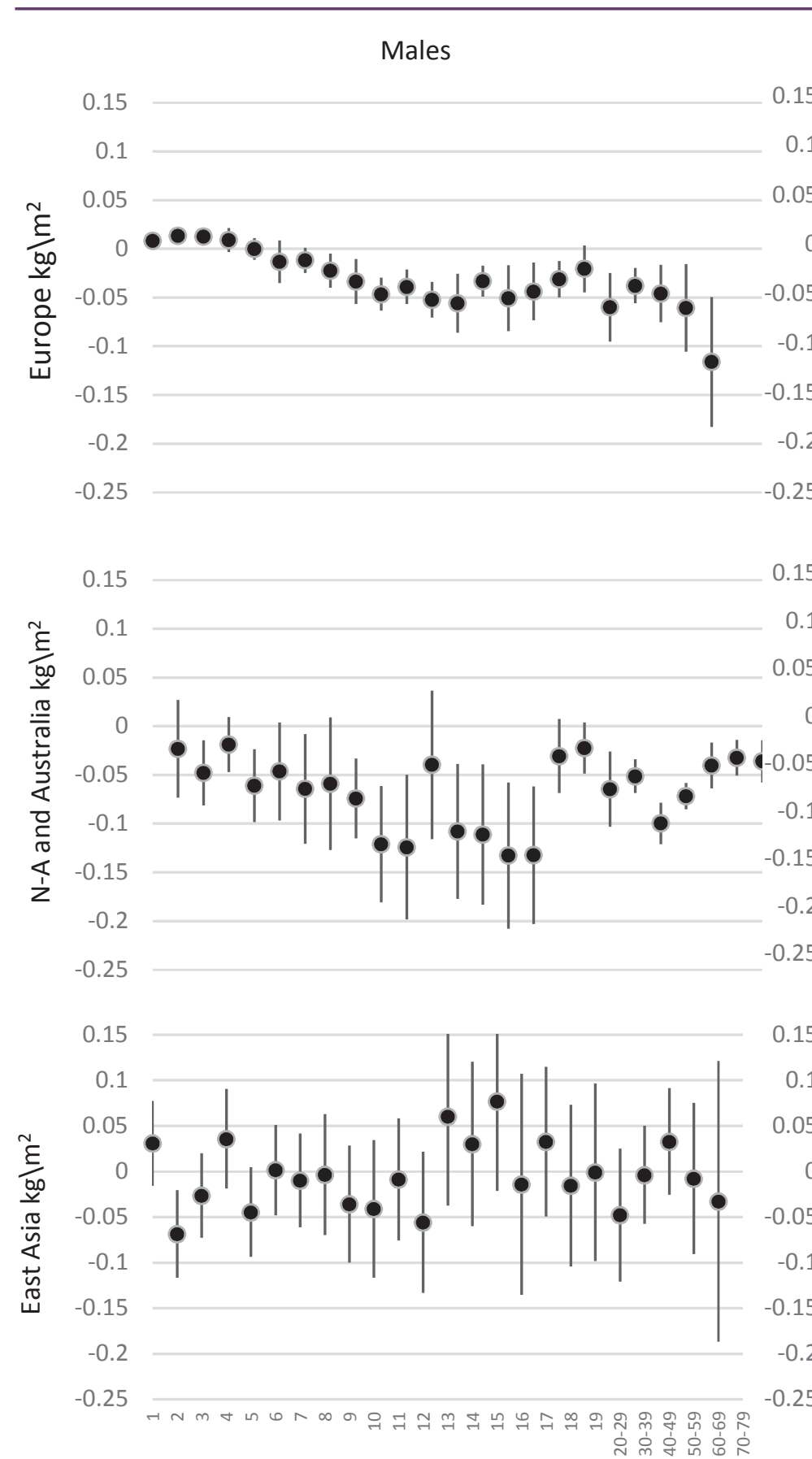

Age
Females

0.15

0.1

0.05

$-0.05$

$-0.1$

0.15

$-0.2$

0.25

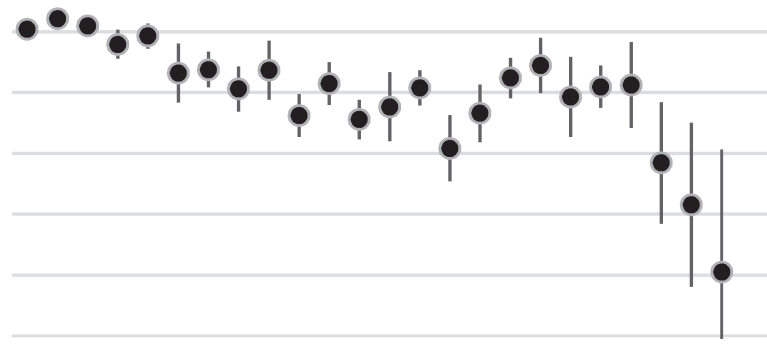

0.15

0.1

0.05

0

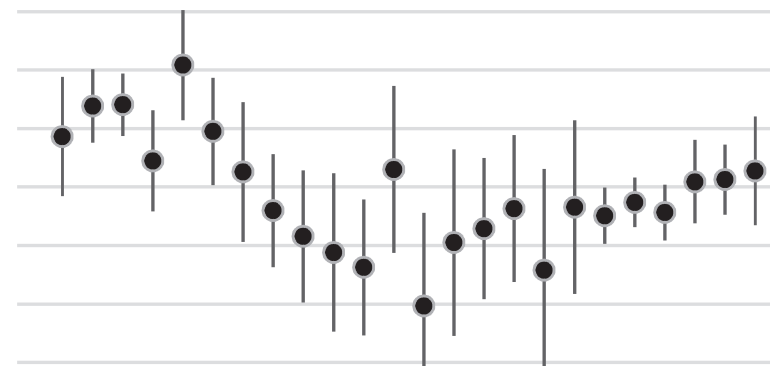

0.15

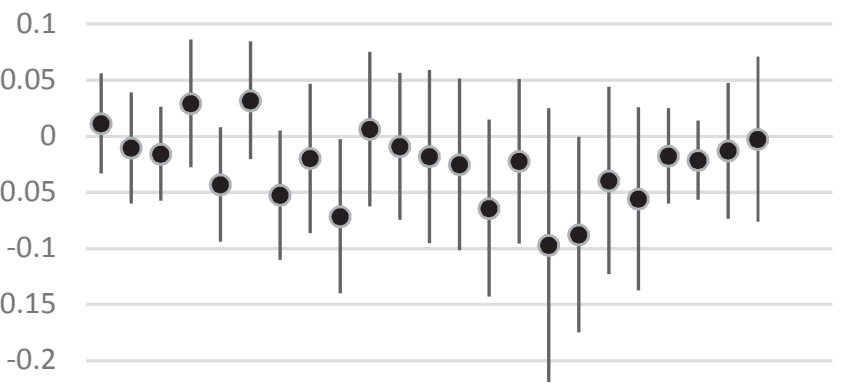

ナ N

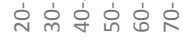

Age

Figure 2 Mean BMI modification effects of parental education with 95\% confidence intervals from 1 until 70 to 79 years of age by sex and cultural-geographic region.

Figures 4 and 5 depict the similar decomposition of BMI variance by the cultural-geographic region. Because the results for the intermediate parental education level category were, in general, between the high and low education level categories, they are not shown, but all estimates with $95 \%$ CIs are available in Supporting Information Tables S5-S6. The total BMI variance was greatest in North America and
Australia and smallest in East Asia. In Europe, as well as in North America and Australia, BMI variation was systematically greater in males and females whose parents had low education levels as compared with the offspring of highly educated parents. In most of the age groups, this difference was statistically significant, as seen in the nonoverlapping 95\% CIs (Supporting Information Tables S5-S6). 


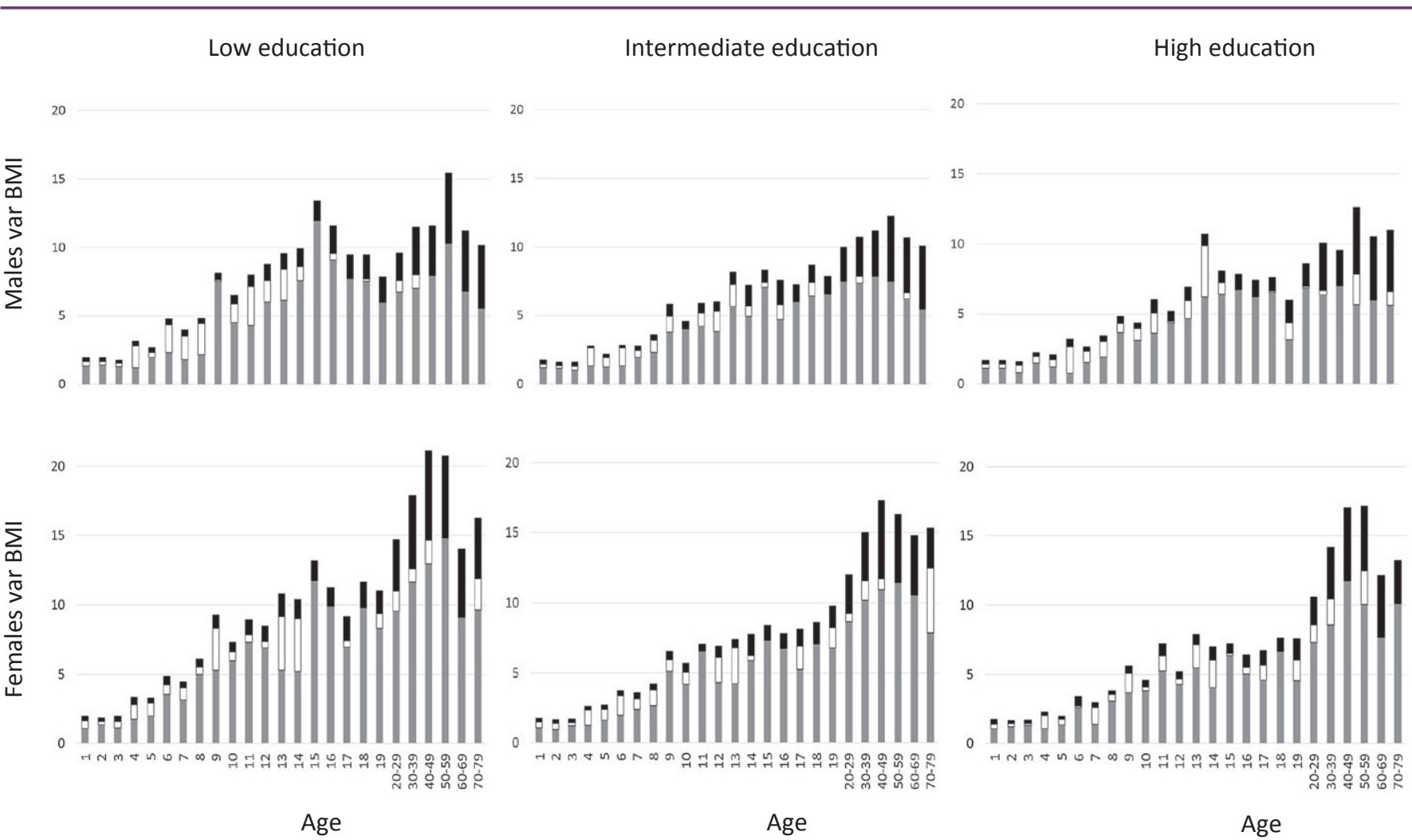

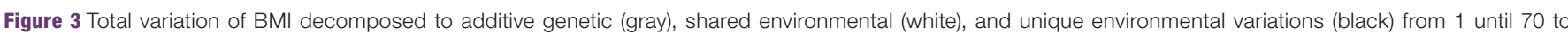
79 years of age by sex and parental education.

When we restricted the analyses to North Americans and Australians with Caucasian ethnicity, the variances decreased somewhat, but they were still larger than in the other cultural-geographic regions and highest in those with low parental education levels (Supporting Information Tables S5-S6).

The differences in the total BMI variation between the parental educational categories were mainly due to differences in additive genetic variation. An exception was North American and Australian boys and girls 11 years of age or younger, for whom the difference in most age groups was mainly due to shared environmental variation. In Europe, we also observed some evidence for the greater role of shared environment in the low parental education level category until 14 years of age, but the differences were not statistically significant. In East Asia, no systematic differences were seen in the total variance of BMI according to parental education.

The gene-environment interaction models confirmed these results (Supporting Information Table S7). In Europe, the additive genetic modification effects were consistently negative, whereas there was more fluctuation in the common environmental modifications effects. In contrast, in North America and Australia, especially in boys under 12 years of age, the shared environmental modifications were consistently negative. However, when using the ACE models, which require more statistical power, only some of these modification effects were statistically significant. In East Asia, the modification effects fluctuated on both sides of zero, and most of them were not statistically significant.

\section{Discussion}

In this study of a very large international data set of twins, we found that higher levels of parental education were consistently associated with lower additive genetic and unique environmental variance of BMI. This result is in accordance with previous twin and molecular genetic studies. In a previous study based on Dutch twin data, children and adolescents whose parents had moderate or low levels of education showed greater genetic BMI variance than those whose parents had high levels of education (3). Danish (12) and US (13) studies of adult twins supported this result by showing greater genetic variation in those with lower education levels than in those with higher education levels. These results are also in line with candidate genes studies in which the effects of low levels of maternal education on children (23) and of one's own education on adults (24) reinforced the effect of FTO gene, the major candidate gene of BMI. Similar results were found for other BMI candidate genes $(25,26)$. However, these molecular genetic studies need replications in other populations, and, preferably, a GWA study using a large sample size should be conducted. Assuming parental education to be a good proxy indicator of the socioeconomic conditions of individuals and their families, our results might indicate that a poorer childhood socioeconomic environment reinforces the influence 


\section{Low education}

25

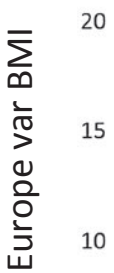

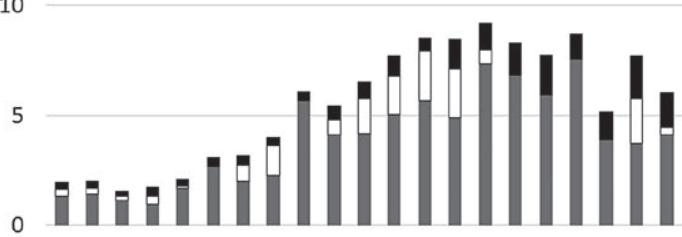

25

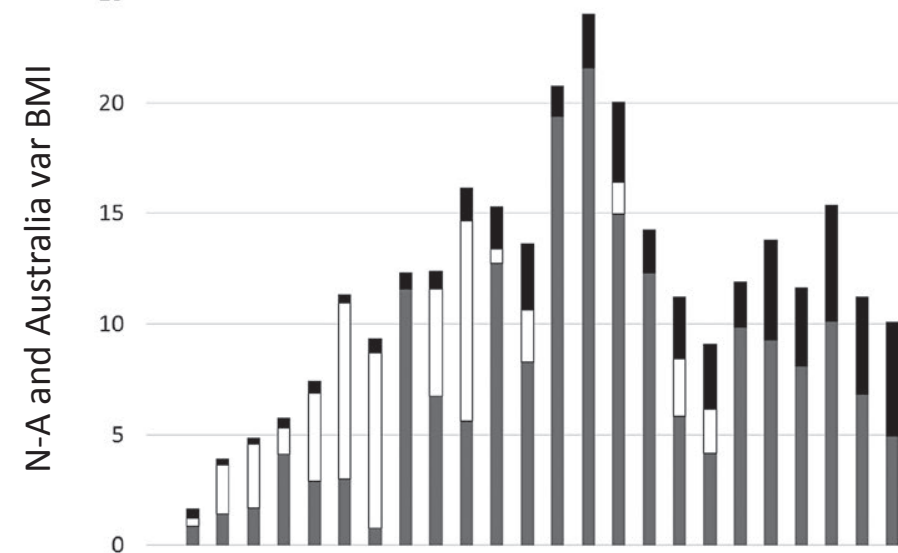

25

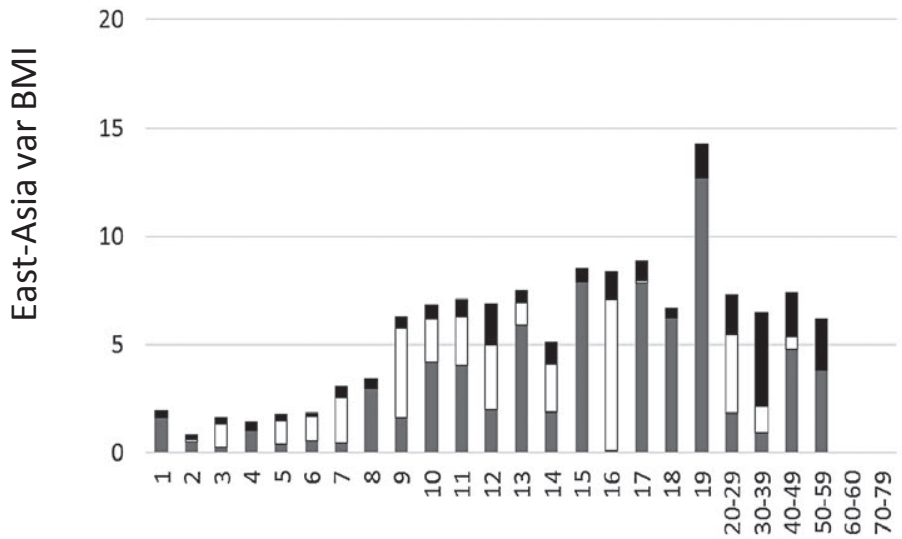

Age
High education

25

20

15

10

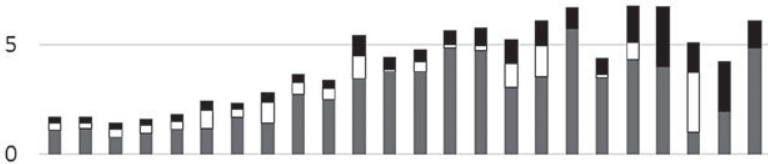

25

20

15

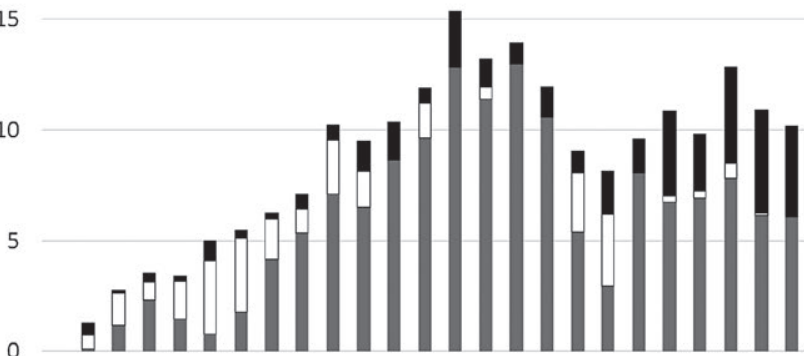

25

20

15

10

0

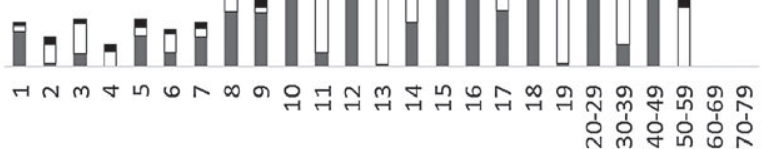

Age

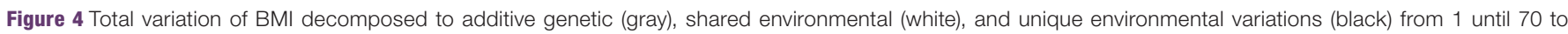
79 years of age by parental education and geographic-cultural region in males. 


\section{Low education}

25

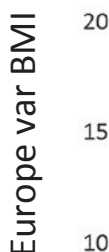
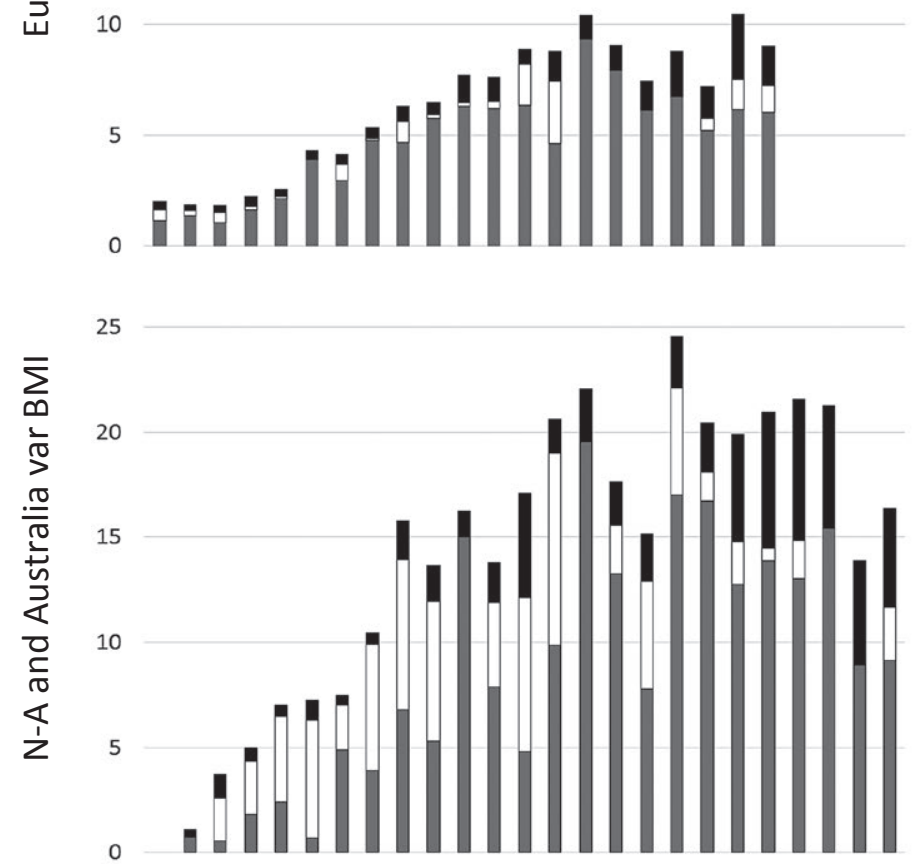

25

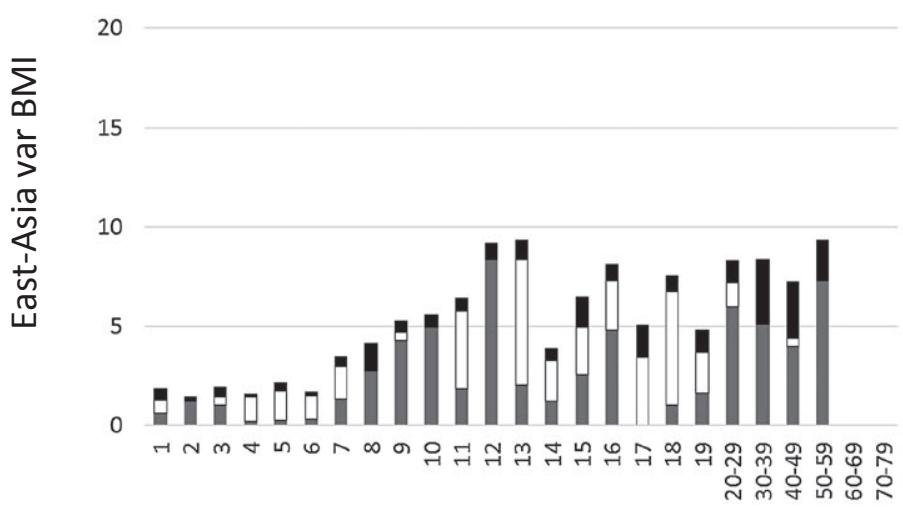

Age
High education

25

20

15

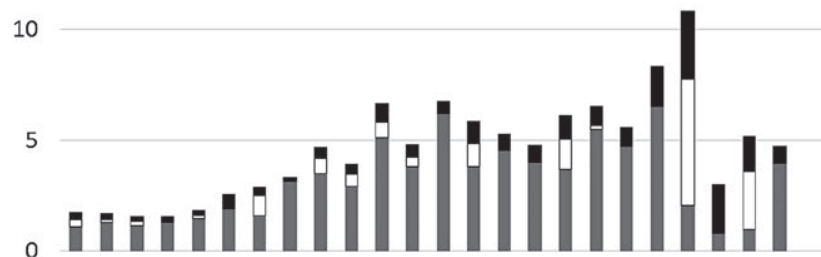

25

20

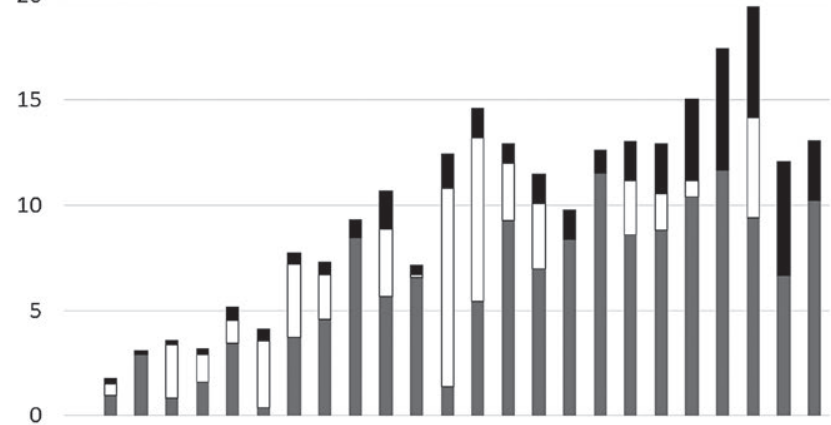

25

20

15

10

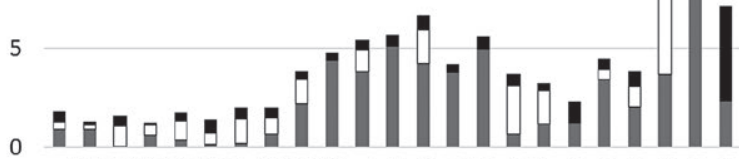

Nmナแ

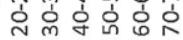

Age 
of genetic factors affecting BMI. However, parental education is also associated with one's own education level in adulthood (27), which is further associated with other factors such as intelligence and personality (28). Thus, the mediating pathways are complex and may change through the life course.

Parental education is associated with BMI after early childhood, which parallels previous population-based studies showing no association (29) or lower BMI (30) in the offspring of mothers with lower education levels before 2 years of age but a clear inverse correlation between the BMI of offspring and maternal education levels after 4 years of age. In early childhood, the lack of association between parental education and offspring BMI might be due to low birth weight associated with low parental education levels affecting BMI over the first years (29). Nevertheless, it may also reflect a change in the genetic architecture of BMI. A negative genetic correlation between education and BMI $(r=-0.28$, standard error $=0.03)$ was found based on cross-trait linkage disequilibrium score regression analysis of large GWA studies (31). As we have reported previously, genetic variation in BMI started to increase after 5 years of age in the CODATwins database (2). This result is in accordance with the previous molecular genetic studies showing that the effects of the FTO gene (32), genetic risk scores of top BMI hits $(33,34)$, and polygenic risk scores from GWA studies (35) started to increase only after early childhood. Thus, it seems that after early childhood, new genetic variants affecting BMI activate and parental education can modify the effects of them, which may be independent of the genetic variants regulating body size in infancy.

The mechanisms explaining the interaction effects between genes and socioeconomic factors on BMI are not clear. In the present study, the association of parental education with mean and genetic variance of BMI persisted through adulthood. This trend might be due to behavior. There is evidence that the FTO gene may affect BMI through food intake self-regulation (36) and eating styles (37), and many genetic risk variants of adult BMI are active in brain areas having an important role in appetite regulation and many cognitive functions $(4,5)$. Findings that the correlations between BMI and a number of personality, cognitive, and brain morphological traits were largely explained by common genetic factors further support the mediating role of brain function (38). It is thus possible that the new genetic variance emerging after mid-childhood relates to the child's food intake self-regulation, with children learning better self-regulation in households with higher parental education levels. Childhood social position also relates to factors such as diet, adverse childhood experiences, and physical activity (39). There is evidence that physical activity can modify the association between the BMI genetic risk score and BMI (40), and parallel results have been found in a twin study showing greater genetic variance of BMI and other obesity indicators in sedentary persons as compared with those who are physically active (41). However, the background mechanisms may go even deeper in the field of neurophysiology. Subordinate female rhesus monkeys had higher caloric consumption than dominant monkeys (42). In addition, starlings with a disadvantaged early life environment were fatter in adulthood and spent more effort for food gathering than those with more advantaged early life environments (43). Although comparisons between species should be treated with caution, these results may suggest deep neurophysiological pathways between early life social position and later eating behavior.

When comparing the geographic-cultural regions, parental education was more strongly associated with BMI in North America and Australia than in Europe and East Asia. Thus, obesogenic environment may reinforce the association between BMI and parental education because the population level mean of BMI is much higher in North America and Australia than in the other two regions (1). This would suggest that the factors affecting BMI at the population level have stronger effects on those having social and/or genetic susceptibility to gain weight. There has been discussion regarding which specific societal factors are behind these region-level differences in BMI, but the results are inconclusive (44). However, our findings suggest that identifying socioeconomic factors associated with the increase of BMI would have beneficial effects, especially on those who are most vulnerable to gaining weight. In addition, societal factors other than obesogenic environment may lead to the weaker effect of parental education on BMI in East Asia. For example, because of cultural differences, food consumption may be differently associated with social factors in different cultural-geographic regions, even in those with the same obesogenic levels in the environment. More detailed measures of macro-environment would be needed to further disentangle the effect of these societal factors.

In most of the age categories, the differences in BMI variance were mainly due to the greater additive genetic variance in the lower parental education level category. However, especially in North America and Australia, this difference was due to greater shared environmental variance in boys and girls at 11 years of age or younger. A Finnish twin study also found that environmental factors shared by co-twins explained a share of BMI variation at 11 to 12 and 14 years of age in children whose parents had limited education, but this variance component was not present at 17 years of age (14). Disentangling shared environmental and additive genetic effects requires considerable statistical power (45), and thus it is possible that these divergent results within Europe are just because of sample variation. However, these results suggest that in childhood, shared environmental factors may contribute directly to the socioeconomic differences in BMI, at least in some societies, whereas in adolescence and adulthood, parental education affects BMI mainly by modifying genetic effects.

Our data have strengths but also have limitations. The main strength is the large sample size, which allowed us to construct and test models in narrow age groups and offered the required statistical power to analyze the effect of parental education over the life-span. Further, we were able to analyze these differences between cultural-geographic regions representing different obesogenic levels in the environment. A limitation is that our data are heavily biased toward Caucasian populations following the Westernized lifestyle, thus limiting statistical power in East Asia. New data collections in East Asia and in other non-Westernized cultural contexts would thus be warranted, especially because we found evidence that there may be substantial differences in the effect of parental education on BMI between more and less obesogenic societies. In addition, our data come from multiple sources, which may differ in representativeness and other factors potentially affecting the strength of found associations.

\section{Conclusion}

We found clear evidence that higher parental education level is associated with lower BMI and less genetic and environmental variation of BMI over the life-span. The critical period is located just after early childhood, when BMI variation begins to increase. In addition to genetic variance, especially in late childhood, the environment shared by co-twins and siblings can be important. The educational 
differences are particularly prominent in North America and Australia. The socioeconomic position of the family affects BMI partly by modifying genetic factors, and the effects on BMI are long lasting, as they are present through adulthood, especially in obesogenic societies. $\mathbf{O}$

\section{(c) 2019 The Obesity Society}

\section{References}

1. NCD Risk Factor Collaboration. Trends in adult body-mass index in 200 countries from 1975 to 2014: a pooled analysis of 1698 population-based measurement studies with $19 \cdot 2$ million participants. Lancet 2016;387:1377-1396.

2. Silventoinen K, Jelenkovic A, Sund R, et al. Genetic and environmental effects on body mass index from infancy to the onset of adulthood: an individual-based pooled analysis of 45 twin cohorts participating in the COllaborative project of Development of Anthropometrical measures in Twins (CODATwins) study. Am J Clin Nutr 2016;104:371-379.

3. Silventoinen K, Jelenkovic A, Sund R, et al. Differences in genetic and environmental variation in adult body mass index by sex, age, time period, and region: an individual-based pooled analysis of 40 twin cohorts. Am J Clin Nutr 2017;106:457-466.

4. Turcot V, Lu Y, Highland HM, et al. Protein-altering variants associated with body mass index implicate pathways that control energy intake and expenditure in obesity. Nat Genet 2018;50:26-41.

5. Yengo L, Sidorenko J, Kemper KE, et al. Meta-analysis of genome-wide association studies for height and body mass index in 700000 individuals of European ancestry. Hum Mol Genet 2018;27:3641-3649.

6. McLaren L. Socioeconomic status and obesity. Epidemiol Rev 2007;29:29-48.

7. Shrewsbury V, Wardle J. Socioeconomic status and adiposity in childhood: a systematic review of cross-sectional studies 1990-2005. Obesity (Silver Spring) 2008;16:275-284.

8. Fontaine KR, Robertson HT, Holst C, et al. Is socioeconomic status of the rearing environment causally related to obesity in the offspring? PLoS One 2011;6:e27692. doi:10.1371/journal.pone.0027692

9. Rokholm B, Silventoinen K, Angquist L, Skytthe A, Kyvik KO, Sørensen TIA. Increased genetic variance of BMI with a higher prevalence of obesity. PLoS One 2011;6:e20816. doi:10.1371/journal.pone

10. Rokholm B, Silventoinen K, Tynelius P, Gamborg M, Sørensen TIA, Rasmussen F. Increasing genetic variance of body mass index during the Swedish obesity epidemic. PLoS One 2011;6:e27135. doi:10.1371/journal.pone.0027135

11. Silventoinen K, Huppertz C, van Beijsterveldt CE, Bartels M, Willemsen G, Boomsma DI. The genetic architecture of body mass index from infancy to adulthood modified by parental education. Obesity (Silver Spring) 2016;24:2004-2011.

12. Johnson W, Kyvik KO, Skytthe A, Deary IJ, Sørensen TIA. Education modifies genetic and environmental influences on BMI. PLoS One 2011;6:e16290. doi:10.1371/ journal.pone. 0016290

13. Dinescu D, Horn EE, Duncan G, Turkheimer E. Socioeconomic modifiers of genetic and environmental influences on body mass index in adult twins. Health Psychol 2016;35:157-166.

14. Lajunen HR, Kaprio J, Rose RJ, Pulkkinen L, Silventoinen K. Genetic and environmental influences on BMI from late childhood to adolescence are modified by parental education. Obesity (Silver Spring) 2012;20:583-589.

15. Silventoinen K, Jelenkovic A, Sund R, et al. The CODATwins project: the cohort description of Collaborative Project of Development of Anthropometrical Measures in Twins to study macro-environmental variation in genetic and environmental effects on anthropometric traits. Twin Res Hum Genet 2015;18:348-360.

16. Fielding RA, Vellas B, Evans WJ, et al. Sarcopenia: an undiagnosed condition in older adults. Current consensus definition: prevalence, etiology, and consequences. International working group on sarcopenia. J Am Med Dir Assoc 2011;12:249-256.

17. Silventoinen K, Jelenkovic A, Latvala A, et al. Education in twins and their parents across birth cohorts over 100 years: an individual-level pooled analysis of 42 twin cohorts. Twin Res Human Genet 2017;20:395-405.

18. Mallick S, Li H, Lipson M, et al. The Simons Genome Diversity Project: 300 genomes from 142 diverse populations. Nature 2016;538:201-206.

19. Posthuma D, Beem AL, de Geus EJ, et al. Theory and practice in quantitative genetics. Twin Res 2003:6:361-376.

20. Jelenkovic A, Yokoyama Y, Sund R, et al. Zygosity differences in height and body mass index of twins from infancy to old age: a study of the CODATwins project. Twin Res Hum Genet 2015; 18:557-570.
21. Purcell S. Variance components models for gene-environment interaction in twin analysis. Twin Res 2002;5:554-571.

22. Neale MC, Hunter MD, Pritikin JN, et al. OpenMx 2.0: extended structural equation and statistical modeling. Psychometrika 2016;81:535-549.

23. Foraita R, Günther F, Gwozdz W, et al. Does the FTO gene interact with the socioeconomic status on the obesity development among young European children? Results from the IDEFICS study. Int J Obes (Lond) 2015;39:1-6.

24. Corella D, Carrasco P, Sorli JV, et al. Education modulates the association of the FTO rs9939609 polymorphism with body mass index and obesity risk in the Mediterranean population. Nutr Metab Cardiovasc Dis 2012;22:651-658.

25. Pigeyre M, Bokor S, Romon M, et al. Influence of maternal educational level on the association between the rs 3809508 neuromedin B gene polymorphism and the risk of obesity in the HELENA study. Int J Obes (Lond) 2010;34:478-486.

26. Lagou V, Liu G, Zhu H, et al. Lifestyle and socioeconomic-status modify the effects of ADRB2 and NOS3 on adiposity in European-American and African-American adolescents. Obesity (Silver Spring) 2011;19:595-603.

27. Bukodi E, Erikson R, Goldthorpe JH. The effects of social origin and cognitive ability on educational attainment: evidence from Britain and Sweden. Acta Sociol 2014;57:293-310

28. Krapohl E, Rimfeld K, Shakeshaft NG, et al. The high heritability of educational achievement reflects many genetically influenced traits, not just intelligence. Proc Natl Acad Sci U S A 2014;111:15273-15278.

29. Morgen CS, Andersen PK, Mortensen LH, et al. Socioeconomic disparities in birth weight and body mass index during infancy through age 7 years: a study within the Danish National Birth Cohort. BMJ Open 2017;7:e011781. doi:10.1136/ bmjopen-2016-011781

30. Howe LD, Tilling K, Galobardes B, Smith GD, Ness AR, Lawlo DA. Socioeconomic disparities in trajectories of adiposity across childhood. Int $\mathrm{J}$ Pediatr Obes 2011;6:e144-e153.

31. Bulik-Sullivan B, Finucane HK, Anttila V, et al. An atlas of genetic correlations across human diseases and traits. Nat Genet 2015;47:1236-1241.

32. Sovio U, Mook-Kanamori DO, Warrington NM, et al. Association between common variation at the FTO locus and changes in body mass index from infancy to late childhood: the complex nature of genetic association through growth and development. PLoS Genet 2011;7:e1001307. doi:10.1371/journal.pgen.1001307

33. Elks CE, Loos RJ, Hardy R, et al. Adult obesity susceptibility variants are associated with greater childhood weight gain and a faster tempo of growth: the 1946 British Birth Cohort Study. Am J Clin Nutr 2012;95:1150-1156.

34. Warrington NM, Howe LD, Wu YY, et al. Association of a body mass index genetic risk score with growth throughout childhood and adolescence. PLoS One 2013;8:e79547. doi:10.1371/journal.pone.0079547

35. Warrington NM, Howe LD, Paternoster L, et al. A genome-wide association study of body mass index across early life and childhood. Int J Epidemiol 2015;44: 700-712.

36. Qi Q, Downer MK, Kilpeläinen TO, Taal HR, Barton SJ, Ntalla I. Dietary intake, FTO genetic variants, and adiposity: a combined analysis of over 16,000 children and adolescents. Diabetes 2015;64:2467-2476.

37. Faith MS, Carnell S, Kral TV. Genetics of food intake self-regulation in childhood: literature review and research opportunities. Hum Hered 2014;75:80-89.

38. Vainik U, Baker TE, Dadar M, et al. Neurobehavioral correlates of obesity are largely heritable. Proc Natl Acad Sci U S A 2018;115:9312-9317.

39. Gustafson SL, Rhodes RE. Parental correlates of physical activity in children and early adolescents. Sports Med 2006;36:79-97.

40. Graff M, Scott RA, Justice AE, et al. Genome-wide physical activity interactions in adiposity - a meta-analysis of 200,452 adults. PLoS Genet 2017;13:e1006528. doi:10.1371/journal.pgen.1006972

41. Silventoinen K, Hasselbalch AL, Lallukka T, et al. Modification effects of physical activity and protein intake on heritability of body size and composition. Am J Clin Nutr 2009;90:1096-1103.

42. Wilson ME, Fisher J, Fischer A, Lee V, Harris RB, Bartness TJ. Quantifying food intake in socially housed monkeys: social status effects on caloric consumption. Physiol Behav 2008;94:586-594.

43. Andrews C, Viviani J, Egan E, et al. Early life adversity increases foraging and information gathering in European starlings, Sturnus vulgaris. Anim Behav 2015;109:123-132.

44. Kirk SF, Penney TL, McHugh TL. Characterizing the obesogenic environment: the state of the evidence with directions for future research. Obes Rev 2009;11: 109-117.

45. Visscher PM, Gordon S, Neale MC. Power of the classical twin design revisited: II detection of common environmental variance. Twin Res Hum Genet 2008;11:48-54 